\title{
CENTRO, MÉTODO Y POESÍA EN CLAROS DEL BOSQUE DE MARÍA ZAMBRANO
}

\author{
Grisel PUJALÁ \\ University of Miami
}

Todo conocimiento descansa en un acto de comprensión previo y en el no menos importante acto de desentrañar el sentido que dicha aspiración cognoscitiva lleva implícita, ya sea por la vía discursiva o por la vía poética. No obstante, el desarrollo del pensamiento racional en Occidente desde la época platónica hasta el siglo XIX ha afirmado a ultranza el divorcio constante entre filosofía y poesía, descartando de esta última toda posibilidad de cognición. La dicotomía no fue tan aparente entre los filósofos pre-socráticos, los que integraron en sí esa rara combinación de reflexión filosófica caracterizada por la persistente búsqueda de la verdad y el adentramiento en la misteriosa y enigmática realidad que constituye el quehacer poético.

Esta antigua unicidad comienza a deteriorarse paulatinamente y alcanza un punto culminante en la Grecia clásica tardía, al expulsar Platón a los poetas de su "República" y calificarlos de creadores de imágenes para estimular la fantasía en vez de iniciar al hombre en la búsqueda de la verdad, dominio, a su juicio, de la filosofía. La fantasía creada por el poeta mueve, influencia y fácilmente estimula las pasiones de la masa a través de la imaginería persuasiva. Dentro de su teoría epistemológica, esta actividad pertenece no al mundo inteligible del conocimiento sino al más efímero mundo visible de la opinión y la conjetura.

Sin embargo, la verdadera causa de la escisión entre pensar filosófico y sentimiento poético tiene sus raíces en el "odium theologicum", desavenencias substanciales entre filósofos y poetas en materias de teología y religión. James Adams, investigador de las antiguas religiones griegas, nos aclara este punto en su libro The Religious Teachers of Greece:

... The most potent cause of strife was the antagonism between poetry and philosophy on the subject of the attribute of the Godhead and his relation with mankind... (pág. 4). 
Fue la conexión, desde sus comienzos, una desavenencia entre el papel que desempeña lo sacro en el acaecer humano; asunto que se convertirá en tópico significativo para filósofos como Martin Heidegger, y en tema preponderante de la obra de María Zambrano.

Poesía y filosofía cohabitan unívocamente en la mente y en el corazón del hombre a fin de dar sentido a su experiencia vital; ambas operan desde el reino de la conciencia; una, desde la lucidez que tantos siglos de racionalismo le otorgan, y la otra se instala en lo que Jung llamó "conciencia eclipsada" o umbral del inconsciente, e invita desde allí a la aprehensión del misterio y el sueño inherentes en el Ser. La unificación de esta profunda dicotomía ha sido ensayada de forma individual a través de los tiempos y por diferentes autores. Se trata de recuperar una forma de conocimiento que se apodere no sólo de la razón, sino que incluya la vida como experiencia integral. En nuestra época, tal es el método propuesto por María Zambrano a través de su obra literaria y muy en particular Claros del bosque: reconciliar la filosofía con antiguas formas de saber relegadas a la subconsciencia individual y colectiva por carecer de lucidez cartesiana, maneras de conocer más cercanas a la forma en que la poesía interpreta y recoge la vida.

Según Zambrano el problema que afrontó el hombre moderno, y que tiene su crisis final en el mundo postmoderno de nuestro siglo, es el haber cortado del ámbito racional los lazos de unión con todos aquellos elementos anímicos e inconscientes que pudiesen ofrecerle un carácter sacro a la existencia, lo cual devino en inhabilidad para descender a los abismos psíquicos de su origen e integrarlos a la totalidad de la vida, no como adversarios de la razón sino en concordancia con la misma.

De esta tarea se ha encargado desde siempre el poeta, y su intuición le ha llevado en ocasiones múltiples a enunciarlo estéticamente. Ya lo señalara Holderlin en su poema "Mnemosyne":

... The heavenly powers

cannot do all things. It is the mortals

who reach sooner into the abyss. So the turn is

with these... (IV, pág. 225).

Heidegger, estudioso de Holderlin y fuente filosófica de Zambrano, al referirse a esta negación y olvido de los hilos de continuidad entre lo sacro, lo humano y lo divino, señala que "not only have the gods and the god fled, but the divine radiance has become extinguished in the world's history" (1971, pág. 91).

Más adelante afirma que la labor del poema es restablecer este vínculo sagrado entre el hombre y los dioses:

... To be a poet is [...] to attend, singing, to the trace of the fugitive gods. This is why the poet in the time of the world's night utters the holy (pág. 94). 
Zambrano nos plantea la doble perspectiva de un método: la sacralidad, vivencia irreflexiva y alianza trascendente del poeta, debe elevarse a categoría cognoscitiva y asumir su lugar al lado de la razón para aquí adquirir lo que jungianamente ha dado en llamarse "proceso de individuación". La fusión no descarta al ser histórico sino que lo une a los substratos psíquicos más antiguos del sentir humano: el estro creador, el ánima, el sueño, la sombra, en síntesis: lo irracional.

Según Jesús Moreno Sanz (1989): "Una psique inmensamente vieja forma la base de nuestra mente y en sus arquetipos colectivos inconscientes hallamos un puente, el vínculo entre el mundo racional de la consciencia y el mundo del puro instinto" (pág. 98).

El abandono milenario de esta energía psíquica —continúa Sanz- ha traído como consecuencia "la vida dominada por la pura conciencia y por ella llevada a una vida artificial y alienada (pág. 98), es decir, la vesania de parte de su naturaleza.

A partir de la generación del 98, dentro del pensamiento español del siglo XX no han faltado filósofos que señalen esta supremacía del método racionalista por encima del mito y la poesía, y los perniciosos efectos que el mismo dejó en la modernidad. Eduardo Subirats (1987) señala esta crisis de fe en la razón que sirve de clima espiritual para los pensadores del 98:

Unamuno cuestiona lo que llama la insubstancialidad, la falta de carácter, la ausencia de identidad, de profundidad en lo histórico, en lo mitológico, en lo poético, inherente al espíritu cartesiano... En consonancia con esta crítica, la obra de Unamuno busca en sus mejores momentos una alternativa en lo poético (pág. 94).

Más adelante (pág. 85) señala Subirats la preocupación de Ortega por el mismo tema y la manera privativa en que éste trata de acercar la razón a la vida:

Ortega, lo mismo que Ganivet o Unamuno, describe en el horizonte de su análisis filosófico los elementos de aquella escisión entre lo histórico y la modernidad que caracteriza la cultura contemporánea. Su alternativa de una síntesis, la razón vital, es afín a la posición unamuniana abocada a lo religioso, el paisaje o lo poético.

Zambrano se hace heredera de este dilema ontológico contemporáneo y ofrece de su propia cosecha el método de la razón poética, proposición que Unamuno dio por imposible: la integración del Ser escindido entre fe y razón.

A diferencia de Ortega, quien centra su filosofía en el ser como existencia y circunstancia histórica y social, va más allá de su maestro cuando afirma mediante su razón poética que existen otros horizontes esenciales para el hombre que se dispone no a buscarlos, sino a encontrarlos, para el que indaga más allá del mero existir, para el que va al encuentro de la totalidad el Ser, "porque en la plenitud [...] no existen las circunstancias. Se borran las circunstancias en la más leve, pálida presencia de la plenitud" (pág. 82). 
Claros del bosque es, entre sus libros, el que mejor expresa su filosofar. Esta obra subraya varios temas que resultan inseparables de su razón poética, como es el concepto de centro, y a la par de éste, el método discontinuo, nuevo plan de vida que acoge, al igual que la Vita nouva de Dante, aspiraciones poéticas, pero que a la vez también admite la inclusión de las consideraciones ontológicas de Zambrano y el alcance del quehacer poético en lo que ella considera la total aprehensión del Ser, la existencia y la vida.

\section{El Centro}

El concepto de "centro" es materia recurrente tanto en filosofía como en la tradición iniciática de Occidente, cuyas raíces se remontan a la antigua escuela pitagórica.

El centro, espacio psicológico y vital, más que ideal es elemento indispensable para la formación y el desarrollo del ser interno del hombre, adiestramiento que consiste en amplificar el nivel introspectivo de manera tal que la atención se desplace de la realidad objetiva y circunstancial a la más sutil y profunda realidad de la conciencia de sí.

Entre las antiguas filosofía que ponderaron la idea de centro está el Estoicismo, escuela que dejó huella en la formación del carácter español a través del pensamiento senequista. Los estoicos apreciaban el recogimiento y la fuerza que generaba un núcleo interior, lugar seguro e imprescindible para la práctica del desapego de las circunstancias tan inseparables de este sistema. Marco Aurelio, uno de sus mejores exponentes, señala en sus Soliloquios: "Busca en tu interior. Dentro de ti esta la fuente de bien, que puede manar de continuo si profundizas siempre" (VII. 59).

Ya desde las primeras páginas, Zambrano deja entrever por el título del libro que éste girará en torno a esa noción básica y en virtud de la cual se desarrolla la obra: "El claro del bosque -indica- es un centro... es otro reino que un alma habita y guarda" (pág. 11). Zambrano retoma y profundiza en ese espacio vacío interior, y desde el actúa para iniciar el comienzo de una mudanza en que la vida se de en toda su plenitud y autenticidad:

... todo organismo vivo persigue poseer un vacío, un hueco dentro de sí, verdadero espacio vital [...] Un ser viviente que resulta tanto más "ser" cuanto más amplio y cualificado sea el vacío [...] Un ser viviente que dirige desde adentro su propia vida a imagen real de la vida (pág. 64).

La importancia de un eje rector con antecedentes místicos en Miguel de Molinos y Kempis prevalece en nuestro días en algunas escuelas psicológicas, como la analítica de Jung y su noción de "mandala" o punto convergente del "Yo Superior", en el Cuarto Camino de Gurdjieff y su "conciencia testigo", y en la más reciente escuela de Psicología Transpersonal promulgada por Ken Wilber y Stanislav Grof. Todos los métodos de auto-conocimiento y explora- 
ción de áreas remotas del ser hacen énfasis en la creación de un mecanismo cognoscitivo superior al ego (sustentador de las funciones de la mente racional), que actúe como centro directriz de toda la actividad de la conciencia humana.

Claros del bosque se inscribe en esta noción y es explícito en cuanto a las funciones desempeñadas por dicho centro y la relación del mismo con la totalidad del hombre. Se trata de iniciar un proceso de honda transformación que repercuta en todos los ámbitos de la vida:

El movimiento más íntimo no puede ser otro que el del centro mismo. Y esto aun cuando se entienda el vivir como una exigencia de íntima transformación. La virtud del centro es atraer, recoger en torno todo lo que anda disperso (pág. 59).

Pero los antecedentes ontológicos del centro en Zambrano van aún más lejos. Existen en su libro ecos del concepto triádico del Ser propuesto por los neoplatónicos. De acuerdo a esta tradición, el Ser comprende tres momentos: el "Ser en sí", o Ser como causa; el "Ser sale de sí", donde la causa deviene en manifestación; y, finalmente, el "Ser regresa a sî", es decir, el efecto retorna a la causa (lo cual implica un desplazamiento interior o toma de conciencia por parte del individuo). El Ser primordial, causa eficiente y final de todas las cosas, genera un impulso creador y sale de su propio aislamiento que es a un tiempo su Ser originario y su meta, de forma que la totalidad del Ser se inscribe en un movimiento circular, "punto privilegiado" al decir de María Zambrano, que, una vez activo, se encarga de todo el proceso de transformación inherentes al hombre que despierta a la vida:

... El centro del ser humano actúa durante la primera etapa de la escala ascendente de la persona, de un modo que responde al sentir originario [...] el centro es, ante todo, inmóvil, dotado de poder de atracción, ordenador [...]. La etapa siguiente comienza en virtud de una transformación que ha tenido que darse ya sintiendo la necesidad y la capacidad del centro de moverse, de transmigrar a un punto nuevo.

Es la etapa de la quietud. El centro no está inmóvil sino quieto [...]. Se ha cumplido una transformación decisiva, se inicia una "Vita nouva" (pág. 59).

Al referirse a la meta final de toda ansia cognoscitiva, la autora vuelve de nuevo sobre el tema para señalar que, en los camino iniciáticos donde el hombre emprende la exploración de sí, la meta consiste en descubrir la sabiduría contenida en el "punto absoluto", proceso que se realiza a medida que el ser individual regresa a las fuentes originarias. "En la vía del conocimiento, - dice- según se abre la conversión del punto de referencia en punto absoluto, éste se hace visible" y hace énfasis en que el "punto absoluto es recinto en el que no siempre se ha entrado por sentirlo vedado, extraño y hasta irreal. Es el punto abierto en el círculo..." (pág. 125).

El conocimiento que encierra, debido a su índole superior, no está abierto al escrutinio de formas convencionales de razonamiento, es una forma de saber 
difícil de lograr ya que depende de la capacidad transformadora del centro interior en relación a la conciencia:

penetrar en él $[\ldots]$ sería ciego error $[\ldots]$ sería su allanamiento. Lo que presenta circularmente cerrado, es imagen que porta el mandato que debe ser recorrido ese cerco. El cerco se transforma en cárcel si se logra entrar en el por la violencia del entendimiento que tantas veces en Occidente se ha ejercido (pág. 125).

Desentrañar "la metáfora del corazón" resulta en una aproximación más honda a la proposición de un centro.

El símbolo del corazón no se limita aquí simplemente a ejemplificar una metáfora en virtud de ser conocido recipiente del sentir humano, connotación que le caracteriza como símbolo tópico en no pocas literaturas.

Hay un sigilo iniciático en dicho planteamiento. Proclo, filósofo neoplatónico, en su libro La Teología de Platón ofrece una serie de ventajosas explicaciones sobre el concepto de los centros como verdaderos generadores de energía en el cuerpo humano, centros que aparecen relacionados en Claros del bosque con la función del corazón. Según Proclo, el cuerpo físico tiene tres centros de energía importantes. El segundo de estos centros productor de energía mental está situado en el cerebro, y rige las actividades racionales del hombre.

El primer centro llamado "la fuente" y situado en el corazón, genera una energía que se emplea en el incremento de la conciencia espiritual del hombre, y es además fuente de la vida. Con el centro racional opera el hombre intelectual y con el centro del corazón funciona el iniciado y desde allí esparce la luz suficiente para controlar las actividades del cuerpo físico y la actividad racional del cerebro.

En Claros del bosque aparecen una multiplicidad de centros, cuyas funciones están ligadas a las del corazón:

Aparecen estos soles como centros luminosos, más o menos lucientes en el sentir y en todos los actos del conocimiento que al sentir siguen y obedecen, y su irradiar está ligado con la función del corazón, con su poder vivificante. Todo centro vital vivifica. Y de ahí que el corazón ya desde la "fysis" sea el centro entre todos (pág. 69).

Eco tal vez del iluminismo, el lugar del corazón es centro de revelaciones hacia el que confluye toda la actividad del espíritu humano. Para Zambrano esta revelación no se verifica por la vía racional, ya que de este quehacer sólo se obtienen la nada y el vacío, condiciones humanas resultantes de la excesiva indagación en el conocimiento ya sea empírico o abstracto (epistema o matesis). El centro del corazón apunta hacia otros caminos de conocimiento como la "pathesis" o experiencia sentida, la "pistis", honda experiencia de la fe, los llamados "estados xenofrénicos" como el sueño, la visión y la revelación, y la "gnosis", conocimiento que no se enseña pues no tiene explicación intelectual 
posible sino percepción intuitiva y sólo puede ser "remembered, recognized or known" (Walker, 1983, pág. 100).

El filosofar de Zambrano nos guía a la conclusión de que el hombre aspirante a la excelencia vital y a la trascendencia del espíritu debe situarse en el centro superior del corazón y desde allí iniciar un nuevo proyecto de vida.

La insistencia en el conocimiento aprehendido sólo desde la razón discursiva no presenta soluciones eficaces a la condición humana. La alternativa de Zambrano radica en desarrollar formas "oblicuas", no lineales, de conocimiento, donde nada se busque ni se pregunte, (reminiscencias del quietismo). Zambrano apunta hacia la supremacía de la revelación por encima del raciocinio y parece indicar que donde existe revelación, el conocimiento, tal y como lo entendemos con la razón, es prescindible: "todo es revelación, todo lo sería de ser acogido en estado naciente" (pág. 51) y ésta, la revelación, sólo es abordable por el hombre que despierta a la libertad del ser y descarta "la presencia de la intención, sin otra finalidad que la fidelidad al ser, en la vida que se abre". La vida tiene dos alternativas: el camino de la circunstancia o el camino del ser, "despertar naciendo o despertar existiendo" (pág. 22).

\section{El método}

El centro y su proyecto de vida nueva, como cualquier otro designio, lleva parejo la aplicación de un método que, una vez puesto en práctica, no queda circunscrito a ciertas áreas del pensamiento en detrimento de otras, como es el caso de la filosofía moderna, sino que es capaz de adecuar todos los ámbitos vitales y que abarque todas las zonas de la vida. La lógica — nos dice- no ocupa todo nuestro tiempo reflexivo. Hay vastas áreas del pensamiento entretenidas por el ensueño, la imaginación, y constituyen espacios abiertos que quedan libre, al margen de la razón, y que necesitan y reclaman un método que los valore y los contenga.

Se adscriben a dicho proyecto contornos de la vida tan significativos como la intuición, la percepción, la revelación, la belleza, el sentimiento. Es notable señalar que es este último el que en realidad otorga valor a toda apreciación no sólo estética sino objetiva y racional; las cosas interesan porque hay alguien que las ama y crecen en importancia en la medida en que alguien las necesita. El método de la autora incluye a la vez el sentimiento, la contemplación estética y el quehacer poético, componentes vitales que, a su juicio, dan sentido y valor a la existencia. George Santayana señala en su libro The Sense of Beauty la propiedad valorativa del sentimiento al declarar que "values spring from the immediate and inexplicable reaction of vital impulses, and form the irrational part of our nature, the rational part is by its essence relative; it leads us from data to conclusion or from part to wholes" (pág. 14).

El impulso vital es elemento esencial en el sistema ideal de Zambrano. El "método discontinuo" debe ser como la conciencia y además llevar la alegría 
implícita en la totalidad vital del hombre que hả encontrado "el medio adecuado de expresión de su hasta entonces precaria vida", un método que surja de un "instante intermitente" de la conciencia.

Según expresa Jesús Sanz, al trayectoria del método se efectúa mediante un ascenso en la luz o "anabasis", estado de completo desasimiento y olvido de sí, herencia probable de los místicos españoles y muy en especial de San Juan de la Cruz. A lo anterior debe añadírsele la travesía inversa o "catabasis", descenso abismático a los orígenes del ser, "no hay infierno — dice Zambranoque no sea la entraña de algún cielo" (pág. 140). El viaje al origen representa un adentramiento en el inconsciente más profundo, personal y colectivo, acto de recuperación del conocimiento o "gnosis" de origen, desterrado por la fillosofía a causa de sus fuentes míticas, las cuales son inalcanzables mediante un simple acto intelectivo.

Tan significativo resulta que estos niveles de la psique sean tomados en consideración al evaluar la totalidad del ser, que la psicología contemporánea los estudia desde una nueva perspectiva. David Feinstein, analista cuidadoso de la mitología como paradigma psicológico, compila y presenta una serie de observaciones de autoridades en el tema, y explica la importancia que los mitos desempeñan en el desarrollo del saber humano, aún en el más distante campo de la ciencia, "... incorporating non-linear knowledge into scientific frameworks is an essential task for the human science and will require new ways of organizing our thinking" (pág. 200).

Joseph Campbell, continúa Feinstein, señaló en una ocasión que el mito "is the revelation to waking conciousness of the power of its own sustaining sources". La mitología, resume Feinstein en su estudio, "embodies the nearest approach of absolute truth, that can be stated in words" (pág. 201).

Zambrano examina precisamente la posibilidad de incorporar la mente mítica a la total manifestación de la conciencia. Al referirse a los "ínferos", "catabasis", lugar de purificación, donde el despertar del sueño psicológico es ineluctable, Zambrano recurre al lenguaje "oblicuo" y simbólico del mito, cuya forma expresiva más natural es, sin lugar a dudas, el lenguaje poético.

El subconsciente guarda claves simbólicas cuyo desciframiento, tanto individual como colectivo, depende de la imagen como espacio de representación. Las referencias mitológicas de Claros del bosque coinciden siempre con la alusión a procesos interiores, sondeos en las áreas profundas del subconsciente. Así, por ejemplo, el mito de Donysos, el "dios oscuro", y la experiencia dionisíaca aparecen como centro del cuestionamiento de la energía de vida, raíz del éxtasis o puro gozo de la existencia, a veces transformado en delirio.

Robert Johnson (1987), recurre a Dionysos como arquetipo de la vida en su más alta plenitud:

To workship Dionysius is to workship the lifeforce. We need to reconnect with the capacity for ecstasy that lies dormant within us [...] Dionysian ecstasy is found in the world of poets and artists and dreamers... (pág. 12) 
Zambrano aboga por la unificación de todas las áreas de la vida de manera que la totalidad de la conciencia pueda participar del gozo vital y de la aprehensión de la belleza, par ello emplea este arquetipo como mito e imagen de fácil asimilación. El método de Zambrano apunta a la fusión como un sentir primigenio y fundamental del hombre que restaure lo religioso (en su acepción de religar), y observa que la adquisición del pensamiento reflexivo, que durante tanto tiempo intentó razonar el orgigen es posterior al sentimiento, y surge como recurso expresivo del sentir. Pensar es, parafraseando a la autora, como raíz y como acto, expresar lo que se siente.

El restablecimiento de los vínculos se debe llevar a cabo mediante la evocación y el uso apropiado del lenguaje poético, lenguaje que mejor expresa la imagen mítica; de forma que cada nivel de la mente queda debidamente tratado según los recursos propios de su discernimiento y al mismo tiempo los niveles deben coincidir en un punto que relacione ser, vida y existencia, elementos todos esenciales, pero que, según la autora, no operan al unísono.

En Claros del bosque hay una notable diferencia entre ser y existencia; esta última viene dada con el nacimiento, pero al ser es menester descubrirlo, lo cual equivale a una "reiteración del nacer", un despertar de la conciencia al "amor pre-existente", al ser supremo. Despertar naciendo es abrir el ser a la luz, sin ninguna otra intención o contenido posible en la conciencia, sin pensamientos, sin imágenes, es decir; el vacío total y la nada, elementos fundamentales para los quietistas, en especial Miguel de Molinos, fuente mística de la autora.

Zambrano elabora sobre el vacío y la nada pero le imprime un carácter diferente a los términos. El genio de María Zambrano consiste, entre otras cosas, en haber mantenido un sutil equilibrio entre pensamiento y sentimiento, $y$ en haber superado sabiamente la época que le tocó vivir. Pertenece cronológicamente al desarrollo y plenitud del existencialismo, no obstante nunca pierde de vista la esencia como antecedente, y en su escritura la nada y el vacío, tan manidos por la filosofía existencialista, recobran una antigua dimensión. No obstante, se instala en la corriente existencialista al representar ésta una profunda inmersión en la vida que dé sentido y plenitud al hombre, una vida no para ser pensada sino para ser vivida de manera única e intransferible. La actualidad del hombre le interesa, pero a diferencia de los existencialistas, no pierde de vista pasado y futuro, dos dimensiones temporales a las cuales el existencialismo restaba importancia.

Zambrano establece una diferencia sustancia entre el ser superior y la personalidad, cuyo centro es el "yo" social y su devenir la existencia. El que existe - dice - no se abre a la visión, va hacia la realidad, existir en "ser fijado como meta o como obstáculo que se interpone" (pág. 23). Existencia es "pretensión de ser"; y el hombre acaba por confundirse al pretender que el "yo" se erija en ser y medida de todo, referencia específica a la categoría ontológica del ser como acto y comportamiento que es patrimonio existencialista. Para Zambrano hay sólo dos alternativas: ser o existir, he ahí las posibilidades humanas. 
El ser permanece escondido, y para descubrirlo se hace necesario el despertar de conciencia del que tanto hablan la mística y la tradición iniciática. El ser, según Zambrano, es pre-existente, precede a la existencia, arriesgada afirmación para sus tiempos: "El ser se revela al llamado de la luz, y ésta es un a priori en el hombre pero que para manifestarse tiene primero que ser anhelada". El hombre es criatura de la luz, pero su sueño psicológico le impide estar consciente de todas las potencialidades del ser. La unión entre la luz y el ser, dice Zambrano, recibe el nombre de revelación, el ser se alimenta de la luz y anda "sin la existencia a cuestas". En el estado unitivo nace la conciencia superior, no de un acto del pensamiento sino de la consumación de la "tragedia".

El hombre así transformado no anda a la deriva sin sentido ni propósito, sino que busca o más bien intuye el sitio de donde "brota la fuente de la vida" (de nuevo San Juan). Y no por eso queda exento de la humana condición y sus avatares sino que está mejor preparado para afrontar la "noche oscura del alma", y gozar de instantes de plenitud en el olvido de sí mismo.

Ser es para Zambrano pulsación, soplo, respiro, presencia que no se exterioriza. Es además vida, trasunto del ser, corriente interior que nos arrastra, "todo lo viviente aquí de algún modo se arrastra, o es arrastrado por la vida" (pág. 107).

Ser y vida se unen cuando el hombre se sitúa en el centro superior del corazón, y si la unión no se efectúa, el ser cesa de estar vivo aunque esto no implica la muerte pues: "para morir hay que estar vivo y para el tránsito viviente" (pág. 57).

Por otro lado, la vida sin el ser es puro impulso disperso sin sentido o dirección, y el ser, escondido y solitario, nunca llega a exponerse del todo. Le toca pues al corazón hacer que la vida recobre su sentir primario, "río de la vida".

\section{La poesía}

En virtud de esta conciencia en que vida y ser coinciden aparece la palabra en una privilegiada función de "dialéctica poética". El discurso zambraniano se efectúa mediante un planteamiento dialéctico, que se desplaza entre aquellos polos que hacen de la vida, según Nietzsche, una obra de arte en virtud de un conflicto mutuo: lo apolíneo y lo dionisíaco. Aparece la reflexión mediante elementos antitéticos, presentados, en muchas ocasiones, en "anticipación", figura dialéctica de pensamiento mediante la cual Zambrano adelanta razonamientos que se resuelven en una integración vital. Así aparecen: ser/existencia, despertar existiendo/despertar naciendo, método discursivo/método poético, búsqueda/entrega, lucha/abandono, dormir/despertar, descenso/ascenso, ceguera/ luz, infierno/cielo, Atenea/Medusa.

Lo apolíneo se inscribe en la categoría fïlosófica que es formalidad, búsqueda del conocimiento, historia, lucidez, medida, control, descenso, lucha, 
mientras que lo dionisíaco se inscribe en la categoría poética que es hallazgo, entrega, abandono, desmesura, lo consustancial del rapto y el éxtasis de la fuerza de vida. Ambas categorías, conocimiento filosófico y éxtasis poético, devienen en una síntesis vital de articulación con lo sacro.

Pero si su estructura es dialéctica, su vía de exploración es poética. Para Zambrano la palabra poética es acto de fe, mediación cuyo sentido es el descubrimiento de lo experiencial del ser. Consecuentemente, convoca la palabra no pronunciada, la palabra original y motivo de toda esencia, palabra que no implica comunicación sino comunión con el ser, divina vibración, música de origen, palabra perdida que equivale al nombre de Dios.

Su palabra apunta hacia la exploración de otras realidades que son causa y fin de la existencia, se ha unido - nos dice- en el ser la palabra que estudian los Vigías del Verbo. Para Zambrano la palabra, más que vehículo de expresión, es vivencia directa del ser del hombre que, según Heidegger, "se funda en el habla".

Ahondando aún más en los orígenes sacros de la palabra, Charles Vachot explica que un estudio profundo del lenguaje puede llegar a convertirse en vía de exploración espiritual. Señala Vachot además que la palabra recorre cuatro estadios ascensionales comenzando por la palabra común, articulada y sonora, para luego pasar a la palabra intermedia que es vibración sutil aunque aún sonora, a continuación viene la palabra inteligible pero no expresada y finalmente la palabra que es tendencia hacia la Idea "cuya sustancia no es otra que el Principio del Verbo" (pág. 33). En los últimos dos niveles la palabra pasa a ser energía creadora, fuerza de vida, punto intermedio en la relación de lo humano y lo divino.

El filosofar poético de Zambrano se remonta a las fuentes primarias de la palabra: "Ia palabra perdida, late en la respiración misma que guarda el secreto del amor divino-humano" (pág. 30). Vista desde esta perspectiva la palabra se convierte en revelación, poesía, metafísica, tres elementos claves en el quehacer literario de María Zambrano. Son -nos señala—otras formas de conocimiento que se poseyeron alguna vez "poéticamente, litúrgicamente, metafísicamente". La palabra poética va preñada de belleza y de mitos, espejo de una experiencia profunda del misterio de la vida y vínculo de lo humano y lo divino. De ahí que toda su obra literaria sea un constante acercamiento a esas fuentes, no por la vía conceptual sino por la palabra "ontofánica". Octavio Paz afirma que "la poesía es la manifestación verbal, la encarnación en palabras, de la mitología, de ahí que la función mítica sea casi indistinguible de la función poética".

La razón poética ofrece pues una trayectoria que se desplaza de lo más apariencial, pasa por el concepto para luego alcanzar los lugares más profundos del sentir humano y, desde allí, recuperar el conocimiento del origen, el que, como señalamos anteriormente, no se adquiere por vías discursivas y reflexivas sino por la visión, que restituye lo sacro al quehacer humano como paso intermedio hacia lo divino. 
El lenguaje poético, portador de símbolos y evocaciones del misterio de la vida, sirve a Zambrano para llevar a cabo ese recorrido, en apariencia fragmentado, del filosofar poético, pero que guarda la estructura interior de todo lo que tiene un centro sustentador. La poesía no pregunta sino intuye las fuentes del misterio del origen, de donde fluye todo ser. La poesía sirve al artista de vínculo esencial con lo perpétulo, raíz de toda fuerza creativa, artística, generadora de belleza, "Lo permamente lo instauran los poetas, Hölderlin dixit" (Heidegger, 1971, pág. 106).

Claros del bosque es un excelente ejemplo del logro sustancial del método de la razón poética. Tanto por su filosofía como por su sentido estético la obra demuestra una genuina preocupación por el despertar del ser a la realización de la belleza y de la mística, apelando esta última a su etimología primera de aquello que ha quedado oculto o escondido. La razón poética es dialéctica de la palabra: la palabra conceptual, la apoderada de la historia, la responsable de la escisión entre el ser y la vida y la palabra poética sincera, reveladora y vínculo estrecho entre ser y vida, entre lo sacro y lo profano.

La finalidad de la razón poética es la búsqueda de una rehumanización de las cogitaciones filosóficas de manera que incluyan indistintamente sensación, sentimiento, intuición y pensamiento, logro eficaz del centro superior del hombre y que el status epistemológico del racionalismo moderno desdeñó por irracional y en cierta forma silenció.

La línea matriz del pensamiento de Zambrano se inscribe en un esfuerzo de integración de lo racional y lo poético, fruto de una labor solidaria entre sensibilidad e inteligencia para así reconciliar, parafraseando a la autora, la rebelión de la vida contra la soberbia de la razón.

\section{BIBLIOGRAFÍA}

ADAMS, James. 1909. The Religious Teachers of Greece, Edinburgh, T. \& T. Clark.

CIOCCHINI, Hector. 1984. "Claros del bosque, una filosofía de la noche del ser", Cuadernos Hispanoamericanos 413, pp. 177-182.

FEINSTEIN, David. 1979. "Personal Mythology as a Paradigm for a Holistic Public Psychology", American Journal of Ortho-Psychiatry 49.2, pp. 198-214.

HALL, Manly. 1975. An Encyclopedic Outline of Symbolical Philosophy, Los Angeles, The Philosophical Research Society.

HEIDEGGER, Martin. 1971. Poetry Language and Thought, New York, Harper \& Row.

JOHNSON, Robert. 1987. Ecstasy, Understanding the Psychology of Joy, San Francisco, Harper \& Row.

MARCO AURELIO. 1980. Soliloquios, México D.F., Editorial Porrúa.

MORENO SANZ, Jesús. 1989. "El método en María Zambrano y la tradición filosófica y gnóstica en Occidente", en María Zambrano, Barcelona, Editorial Anthropos. 
NIETZCHE, Friedreich. 1967. The Birth of Tragedy, New York, Random House.

PAZ, Octavio. 1971. Los signos en rotación, Madrid, Alianza Editorial.

ROJO, José. 1983. "María Zambrano: la poética del ser", Litoral 124-25-26, pp. 94-101. SANTAYANA, George. 1955. The Sense of Beauty, New York, Dover.

SUBIRATS, Eduardo. 1987. "Intermedio entre filosofía y poesía", Anthropos, 70-71, pp. 94-99.

WALKER, Benjamín. 1983. Gnosticism, its History and Influence, Wellingborough, Aquarian Press.

ZAMBRANO, María. 1977. Claros del bosque, Barcelona, Seix y Barral. 